\title{
PRINCIPALES REPERCUSIONES DE LA REFORMA TRIBUTARIA EN CHILE
}

\section{MAIN IMPACT OF TAX REFORM IN CHILE}

\author{
Oscar Alfredo Rojas Carrasco \\ Departamento de Postgrado, Universidad Miguel de \\ Cervantes \\ Santiago, Santiago, Chile \\ oscar.rojas@umcervantesecontinua.cl
}

\author{
Fernando Alejandro Herrera Ciudad \\ Departamento de Postgrado, Universidad Miguel de \\ Cervantes \\ Santiago, Santiago, Chile \\ fernando.herrera@umcervantesecontinua.cl
}

\author{
Albino Enzon González González \\ Departamento de Postgrado, Universidad Miguel de Cervantes \\ Santiago, Santiago, Chile \\ albino.gonzalez@profe.umcervantes.cl
}

Fecha de recepción: 12/12/2018 - Fecha de aprobación: 25/04/2019

\section{RESUMEN}

El presente estudio tiene por objeto analizar la reforma tributaria y el cambio impositivo del impuesto a la renta, dado que toda reforma a un sistema tributario trae consigo efectos de carácter distributivos en la sociedad. Dentro del Programa del recientemente asumido Gobierno, se encuentra la Reforma Tributaria como una medida de aumentar la recaudación fiscal, la que pretende lograr, de acuerdo al proyecto de ley, cuatro objetivos: Aumentar la carga tributaria para financiar, con ingresos permanentes, los gastos permanentes de la reforma educacional que se quiere emprender, otras políticas del ámbito de la protección social y el actual déficit estructural en las cuentas fiscales; Avanzar en equidad tributaria, mejorando la distribución del ingreso; Introducir nuevos y más eficientes mecanismos de incentivos al ahorro e inversión; Velar porque se pague lo que corresponda de acuerdo con las leyes, avanzando en medidas que disminuyan la evasión y la elusión. La meta de recaudación del conjunto de las medidas de la Reforma Tributaria será de $3 \%$ del PIB (Producto Interno Bruto). Esta meta se descompone en $2,5 \%$ del PIB provenientes de cambios a la estructura tributaria y $0,5 \%$ del PIB de medidas que reducen la evasión y la elusión, la cifra estimada a recaudar es de US\$8.200.000.000.

PALABRAS CLAVE: Reforma Tributaria; Ley 600; Impuesto a la Renta; Pequeña Empresa.

\footnotetext{
“Visión de Futuro" Año 16, Volumen Nº 23 N², Julio - Diciembre 2019 - Pág. 1 - 20 URL de la Revista: http://visiondefuturo.fce.unam.edu.ar/index.php/visiondefuturo/index URL del Documento: http://visiondefuturo.fce.unam.edu.ar/index.php/visiondefuturo/issue/view/16 ISSN 1668 - 8708 - Versión en Línea

E-mail: revistacientifica@fce.unam.edu.ar
} 


\section{ABSTRACT}

The purpose of this study is to analyze the tax reform and the tax change of the income tax, given that any reform to a tax system brings about distributional effects in society. Within the agenda of the newly assumed government, is tax reform as a measure to increase tax revenues, which aims to achieve, according to the draft law, four objectives: Increase the tax burden to finance, with permanent income, the ongoing expenses of the educational reform which is to be taken, other policies in the field of social protection and the current structural deficit in the fiscal accounts; Advance in Tax Equity, improving the distribution of income; Introduce new and more efficient mechanisms of incentives for savings and investment; Ensure that it is paid as appropriate in accordance with the laws, progress in measures to reduce tax evasion and avoidance. The collection goal of all the measures of the Tax Reform will be $3 \%$ of GDP. This goal is decomposed into $2.5 \%$ of GDP from changes in the tax structure and $0.5 \%$ of GDP from measures that reduce evasion and avoidance, the estimated figure to be collected is US $\$ 8,200,000,000$.

KEY WORDS: Tax Reform; Law 600; Income Tax; Small Business.

\section{INTRODUCCIÓN}

El día 1 de abril de 2014, el gobierno chileno envió un proyecto de reforma tributaria al congreso, con el objeto de reemplazar el sistema de tributación del impuesto a la renta y modificar sustancialmente dicha Ley y el Código Tributario. El miércoles 06 de mayo del 2014, fue aprobado por la Cámara de Diputados, faltando aún la instancia del Senado.

Lo anterior, bajo la necesidad de recaudar mayor tributo para atender los petitorios de los movimientos nacionales populares, principalmente, del sector estudiantil, los cuales exigen una educación gratuita y de calidad, estimando que con esta nueva reforma se recaudarán en régimen, aproximadamente, 8.200 millones de dólares (3,02\% del PIB).

Para cumplir con estas transformaciones sociales y tener la solvencia económica fiscal necesaria y sustentable en el tiempo, esta nueva reforma tributaria efectuará cambios importantes, tales como la disminución de la brecha social en educación, salud y protección social, donde analizaremos los principales cambios, considerando como el de mayor peso lo que refiere al cambio impositivo del impuesto a la renta, entendiendo que en el actual modelo tributario (vigente desde 1984), el impuesto a la renta de personas esta integrado

\footnotetext{
“Visión de Futuro" Año 16, Volumen Nº 23 N², Julio - Diciembre 2019 - Pág. 1 - 20

URL de la Revista: http://visiondefuturo.fce.unam.edu.ar/index.php/visiondefuturo/index

URL del Documento: http://visiondefuturo.fce.unam.edu.ar/index.php/visiondefuturo/issue/view/16

ISSN 1668 - 8708 - Versión en Línea

E-mail: revistacientifica@fce.unam.edu.ar
} 
con el de las empresas, donde los dueños quedan exentos del impuesto global complementario, cuando las utilidades no retiradas quedan invertidas en el ámbito empresarial, dando origen al FUT (Fondo de Utilidad Tributaria) ${ }^{1}$, donde las empresas, que declaran renta efectiva en primera categoría, registran el historial de las utilidades, las que como medios de inversión tienen que cumplir el objetivo de promover el desarrollo.

Toda sociedad organizada, requiere de un Estado que sea capaz de proveer de bienes públicos compatibles con el nivel de vida de sus habitantes y que puedan ser sostenidos en el tiempo mediante una tributación por parte de sus ciudadanos. Un buen sistema tributario debiera ser lo suficientemente eficiente de modo de satisfacer la creciente demanda de servicios públicos que el desarrollo de una sociedad requiere.

En Chile, el Estado tiene varios mecanismos para recaudar los impuestos, uno de los más importantes es el impuesto que las personas pagan por sus rentas. Esta tributación es regida hoy en día por el decreto ley $N^{\circ} 824$ del 31 de diciembre de 1984, el cual establece la forma como los ciudadanos chilenos y extranjeros domiciliados o residentes en el país deben pagar impuesto por sus rentas, sean estas de cualquier origen, ya sea que su fuente de entradas esté situada dentro del país o fuera de él.

Con el tiempo, la sociedad chilena ha alcanzado un mayor desarrollo y bienestar, permitiendo que las personas tengan un mejor nivel de vida. Esto ha traído como consecuencia un mayor gasto público, el que es financiado, en una buena parte, por el impuesto a la renta. Esto último ha llevado a modificar durante estos últimos 15 años varios artículos del decreto ley № 824 , de modo de lograr un mejor y más eficiente uso de esta ley. Pero estos cambios no han sido lo suficientemente efectivos para avanzar con mayor fuerza y eficiencia en la oferta de bienes públicos que Chile necesita para su desarrollo.

Desde el año 2010, diversos organismos, tanto estatales como instituciones académicas para el estudio de políticas públicas, han planteado la necesidad de realizar cambios profundos a la estructura tributaria chilena, de manera que se pueda satisfacer la mayor demanda de bienes públicos que el país necesita, en especial, la educación y la salud. Es por esto que, en el pasado mes de abril, el poder ejecutivo de Chile, envió un proyecto de reforma tributaria al Congreso Nacional para su aprobación y posterior aplicación, el cual modifica el sistema de la tributación de la renta.

Estos cambios al sistema de tributación de la renta apuntan hacia cuatro objetivos básicos, a saber:

\footnotetext{
${ }^{1}$ FUT - Fondo de Utilidades Tributables: Corresponde a las utilidades no retiradas de la empresa y, por tanto, no computadas en la base imponible de los propietarios de la empresa.

"Visión de Futuro" Año 16, Volumen No 23 N², Julio - Diciembre 2019 - Pág. 1 - 20

URL de la Revista: http://visiondefuturo.fce.unam.edu.ar/index.php/visiondefuturo/index

URL del Documento: http://visiondefuturo.fce.unam.edu.ar/index.php/visiondefuturo/issue/view/16

ISSN 1668 - 8708 - Versión en Línea

E-mail: revistacientifica@fce.unam.edu.ar
} 
1. Aumento de la carga tributaria para lograr una mayor recaudación que permita financiar políticas públicas en educación, salud y acortar el déficit estructural de las cuentas fiscales.

2. Lograr equidad tributaria del impuesto al ingreso, en especial, para los micro y pequeños empresarios.

3. Introducir mecanismos que incentiven el ahorro y la inversión de las empresas, en especial, las entidades más pequeñas del país.

4. Establecer medidas explícitas para disminuir los niveles de evasión y elusión tributaria.

\section{DESARROLLO}

\section{Marco teórico}

Centrarse en las reformas al sistema tributario no solo sienta las bases para una sociedad más equitativa, quitándoles más a los que tienen más, sino que también otorga los cimientos financieros para las políticas públicas de largo plazo, capaces de mejorar las condiciones de educación, salud, vivienda, entre otros. Esto no solo permite construir una sociedad más productiva y justa, sino que además viene a responder a la médula de las demandas sociales de Chile.

Dado que el impuesto a la renta será el principal análisis dentro de la reforma en este estudio, se explicará más en extenso para facilitar su comprensión, entendiendo que los impuestos son aportes que los ciudadanos están obligados a pagar por ley, para que el Estado disponga de recursos suficientes para financiar necesidades públicas. Un tipo de impuesto que grava los ingresos que perciben las personas, empresas y otras entidades legales, es el llamado impuesto a la renta, que se clasifica, básicamente, de la siguiente forma:

$>$ Impuesto Global Complementario, que grava a las personas naturales con domicilio o residencia en Chile.

$>$ El Impuesto Adicional a la Renta, que grava a personas naturales y jurídicas, sin domicilio ni residencia en Chile.

$>$ Impuesto de Primera Categoría, que afecta a las personas naturales y jurídicas y se determina en base a rentas efectivas y rentas presuntas.

$>$ El Impuesto Único, que grava a contribuyentes que indica el inciso $1^{\circ}$ del art. 21 de la ley de impuesto a la renta.

$>$ Impuesto Único de Segunda categoría, que grava a personas naturales, trabajadores

\footnotetext{
“Visión de Futuro" Año 16, Volumen Nº 23 N², Julio - Diciembre 2019 - Pág. 1 - 20

URL de la Revista: http://visiondefuturo.fce.unam.edu.ar/index.php/visiondefuturo/index

URL del Documento: http://visiondefuturo.fce.unam.edu.ar/index.php/visiondefuturo/issue/view/16

ISSN 1668 - 8708 - Versión en Línea

E-mail: revistacientifica@fce.unam.edu.ar
} 
dependientes y pensionados.

Por su parte, los contribuyentes se clasifican tributariamente en la primera y/o segunda categoría, dependiendo del tipo de ingresos que obtienen, los primeros reciben rentas del capital y de las empresas; los segundos perciben rentas del trabajo, como es el caso de los trabajadores dependientes e independientes. Todos los contribuyentes, ya sean de primera o segunda categoría de la ley sobre impuesto a la renta, tienen obligaciones por el solo hecho de desarrollar una actividad económica afectada al pago de impuestos.

Viendo el contexto de fondo de este nuevo proyecto y con la finalidad del análisis de la Reforma Tributaria y el cambio impositivo del impuesto a la renta, nos ubicaremos en el modelo actual y en las bases que sustentaron su creación, comparando y evaluando el nuevo modelo propuesto.

\section{Historia del Modelo Tributario}

Según González (2014), experto tributarista, en Charla dictada el día 08 de mayo del 2014 en la Universidad de Talca Sede Curicó, el sistema tributario en Chile hasta el año 1984, "funcionaba sobre la base devengada, entonces existían dos niveles de tributación, un primer nivel en el ámbito de la empresa y un segundo nivel en el ámbito de los dueños" $(\mathrm{s} / \mathrm{p})$.

Existía un impuesto que gravaba a la empresa, que es el mismo impuesto de primera categoría que poseemos hoy en día. En ese tiempo la tasa correspondía al 10\% y existía un global complementario muy similar al actual, con distintos tramos y distintas escalas, y que su tasa máxima, solo para efectos del presente análisis, correspondía a un $45 \%$.

En ambos casos, lo que se gravaba era la renta devengada, suponiendo que la renta era de $\$ 100$, la empresa debería pagar $\$ 10$, los dueños $\$ 45$ y la recaudación fiscal total correspondía, entonces, a $\$ 55$, esto bajo el supuesto de que la renta está afecta a la tasa marginal más alta del G.C.

Año 1984, el país con problemas financieros, una banca en insolvencia, dificultades en toda la actividad económica, ya que muchas empresas estaban quebradas, producto también, en parte, a estas mismas políticas, ya que se adoptó una política de apertura al mundo, lo que significó bajar las tasas aduaneras, haciendo más barata la internación de productos importados. Nuestra industria jamás se preocupó de tener una buena dotación de maquinaria moderna y eficiente, provocando la incapacidad de competir con los productos que llegaban de fuera.

Recapitulando la situación de ese entonces en el país -dificultades financieras, banca insolvente, problemas de productividad con empresas que poseían maquinarias muy

\footnotetext{
"Visión de Futuro" Año 16, Volumen N²3 N², Julio - Diciembre 2019 - Pág. 1 - 20

URL de la Revista: http://visiondefuturo.fce.unam.edu.ar/index.php/visiondefuturo/index

URL del Documento: http://visiondefuturo.fce.unam.edu.ar/index.php/visiondefuturo/issue/view/16

ISSN 1668 - 8708 - Versión en Línea

E-mail: revistacientifica@fce.unam.edu.ar
} 
antiguas y producto de la apertura al mundo- las empresas no fueron competitivas. Baja calidad y precios elevados.

Paralelamente, llegaban profesionales educados en el extranjero, apareciendo los Chicago Boys, quienes crearon el nuevo modelo tributario. Uno de los primeros cuestionamientos efectuados por ellos hacia la norma vigente, pasó por el siguiente interrogante ¿Por qué gravar la empresa?, si, en último término, la empresa no es más que una organización que se da en las personas y que solo podemos concebir fruto de nuestra inteligencia. Entonces, lo que se debe gravar, son los dueños, ya que cuando la empresa tiene utilidades, no es esta la que se hace más rica, sino las personas naturales dueñas de la empresa. Por lo tanto, este primer impuesto no debería ser considerado.

Por otro lado, había una disyuntiva respecto de cómo se concebía la sociedad. Ellos querían una sociedad que se desarrollara entregando las más amplias facultades posibles a las personas y esto significaba, restarle ámbito al Estado.

\section{Modelo Tributario Actual}

Así se llega, finalmente, a plantear un nuevo modelo, el que hoy está vigente, en el que se mantiene el impuesto de primera categoría y global complementario, empresa y dueño, pero cambiando la base, manteniendo la base devengada para la aplicación del impuesto a la empresa y aplicando el impuesto a los dueños en la oportunidad del retiro o distribución de la renta. Además, se incorpora un mecanismo de integración entre ambos impuestos, estableciendo que el impuesto pagado por las empresas constituirá un crédito a favor de los impuestos que graven a los dueños.

“Así las cosas, como el dueño tributarán en función de una decisión que él tome, solo tributará cuando retire la renta, las utilidades pendientes de retiro son las que dan origen al FUT" (González, 2014, p. 89). Entonces, la primera categoría siguió sobre base devengada, con la misma tasa del $10 \%$, por cada $\$ 100$ pesos de renta, el fisco recibía $\$ 10$ y como la base de tributación que grava al dueño, se encuentra sobre la base de la decisión que él tome, se analizan dos situaciones extremas: No retira nada: base imponible $0 \%$, el impuesto $=\$ 0$ o retira toda la renta: si retiraba $\$ 100$, base imponible $45 \%$, pero el impuesto pagado por la empresa es abonado a lo que tendría que pagar el dueño. Entonces deberá pagar $\$ 35$.

Por lo tanto, la recaudación potencial mínima con este modelo era $\$ 10$ y la máxima $\$ 45$. Este nuevo modelo redujo en $\$ 10$, la recaudación potencial máxima, frente al modelo anterior $(\$ 55)$.

\footnotetext{
"Visión de Futuro" Año 16, Volumen Nº 23 N², Julio - Diciembre 2019 - Pág. 1 - 20

URL de la Revista: http://visiondefuturo.fce.unam.edu.ar/index.php/visiondefuturo/index

URL del Documento: http://visiondefuturo.fce.unam.edu.ar/index.php/visiondefuturo/issue/view/16

ISSN 1668 - 8708 - Versión en Línea

E-mail: revistacientifica@fce.unam.edu.ar
} 


\section{Modelo Tributario Propuesto por la Reforma}

Con el modelo propuesto en la Reforma Tributaria, nace un nuevo concepto denominado Renta Atribuida, que difiere del concepto devengado, siendo más amplio que este último, toda vez que entiende como renta algunas partidas respecto de las cuales el contribuyente carece de título o derecho. La empresa de acuerdo a Cross Plaza Tax Compliance \& BPO (2014) "deberá pagar un 25\% de impuesto, señalando la actual reforma en proyecto, una rebaja de tasas, la tasa máxima del G.C. que hoy corresponde a un $40 \%$, se reduciría a un $35 \%$, disminuye la tasa, pero aumenta la base, ya que ahora no se posee la opción en el ámbito del G.C. para no retirar" (p. 90). Toda la renta generada por la empresa se entiende atribuida a los dueños conforme a los porcentajes de participación que posea cada uno en ella.

Según lo señalado, actualmente existen pequeñas empresas que tributan en base al artículo 14bis (a derogar) sobre base retirada, vale decir, si no retiran no existe impuesto ni de primera categoría ni de global complementario. El artículo 14bis opera bajo el modelo vigente, por lo tanto, si no retirara los recursos de su actividad, el Estado presumía que la empresa estaba creciendo y reinvirtiendo y como mecanismo de estímulo no aplicaba impuesto. Por lo tanto, con la nueva reforma, al tener que pagar el impuesto sobre la base de renta atribuida, las empresas dispondrán de menores recursos y deberán recurrir al crédito para financiar sus operaciones, capital de trabajo e inversión, lo que se puede avizorar provocará aumentos de costos, menor producción y probablemente, incremento en el desempleo.

El 14bis, será absorbido por el 14ter, pudiendo las empresas optar por esta alternativa. Bajo esta modalidad la forma de no tener base imponible es destinar todas las utilidades, diferencia entre ingresos y gastos, a la inversión, vía compra de bienes, ya sean destinados al activo fijo o al activo realizable. Lamentablemente, esta modalidad de tributación no sería de utilidad para las empresas de servicios, ya que estas no tienen activos realizables y no requieren gran inversión en activo fijo.

También, la reforma tributaria considera cambios normativos al actual sistema impositivo chileno, dentro de los cuales se encuentra la eliminación del FUT (Fondo de Utilidades Tributables) y que corresponde a las utilidades no retiradas de la empresa y, por tanto, no computadas en la base imponible de los propietarios de la empresa.

Los fundamentos bajo los cuales se creó el FUT en la década de los 80, a raíz de la coyuntura económica que vivía el país en esa época, fueron el mecanismo utilizado para incentivar la inversión como apoyo a la generación de empleo y fomento al crecimiento económico nacional. En la actualidad ya no están estas condiciones porque el sistema

\footnotetext{
"Visión de Futuro" Año 16, Volumen No 23 N², Julio - Diciembre 2019 - Pág. 1 - 20

URL de la Revista: http://visiondefuturo.fce.unam.edu.ar/index.php/visiondefuturo/index

URL del Documento: http://visiondefuturo.fce.unam.edu.ar/index.php/visiondefuturo/issue/view/16

ISSN 1668 - 8708 - Versión en Línea

E-mail: revistacientifica@fce.unam.edu.ar
} 
financiero chileno cuenta con una solidez similar a los países desarrollados, y que en la última crisis financiera mundial así quedó demostrado. Sin embargo, no todas las empresas tienen acceso al sistema financiero, por lo que la eliminación del FUT puede afectarlas.

En el análisis se ejemplifica como la eliminación del FUT aumentará la carga tributaria de las empresas y de los dueños, debido al cambio en la base de la tributación, de devengada y retirada a atribuida, lo que estaría cumpliendo con el objetivo de recaudar una mayor cantidad de dinero, aún cuando esto desincentivará la inversión.

Dentro de los cambios planteados en la reforma, se encuentra la eliminación del FUT (Fondo de Utilidades Tributables) que dicho de manera sencilla, son las utilidades no retiradas que genera una empresa, las que al no ser computadas en la base imponible, los socios no pagan impuesto por ello. Sin embargo, una vez que las utilidades son retiradas, se debe pagar el impuesto global complementario con la tasa progresiva que corresponda a la magnitud de la base imponible, otorgándose como crédito el impuesto que pagó la empresa cuando se generaron las utilidades. Es decir, si la persona queda gravada con una tasa media de global complementario de $30 \%$, atendiendo a que opera como crédito el impuesto pagado por la empresa, actualmente con tasa $20 \%$, el desembolso tributario a solventar por el dueño será solo del orden del 10\%.

Con esta eliminación del FUT, los dueños de las empresas deberán tributar por la totalidad de las utilidades atribuidas por la empresa y no solo sobre las utilidades retiradas. Dado que el FUT nace con la finalidad de aumentar la inversión y fomentar el desarrollo económico del país, se cree que esta reforma puede ir en desmedro del ahorro y disminuir la inversión de las pequeñas y medianas empresas.

Con el objetivo de sentar precedentes, el FUT tuvo su origen en una situación económica particular. En el año 1984 las empresas chilenas no tenían capacidad de financiar sus inversiones. En primer lugar, el sistema bancario estaba paralizado después de la crisis de los años 1982-1983. En segundo lugar, el Estado de Chile estaba en mora de su deuda externa, lo que hacía imposible que las empresas pudieran buscar financiamiento en el exterior. Por último, nuestro mercado de capitales era casi inexistente el año 1984. Ante esta situación las empresas solo podían financiar sus inversiones usando sus utilidades retenidas. En este contexto el FUT tenía sentido económico.

La situación de Chile hoy es completamente distinta. El sistema bancario chileno tiene una profundidad similar a muchos de los países desarrollados y ha mostrado su fortaleza en la última crisis financiera mundial. El mercado de capitales ha tenido un gran desarrollo en las últimas décadas, permitiendo que las grandes empresas puedan financiarse con emisión de bonos y acciones. Por último, las empresas pueden obtener financiamiento en el exterior

\footnotetext{
“Visión de Futuro" Año 16, Volumen Nº 23 N², Julio - Diciembre 2019 - Pág. 1 - 20

URL de la Revista: http://visiondefuturo.fce.unam.edu.ar/index.php/visiondefuturo/index

URL del Documento: http://visiondefuturo.fce.unam.edu.ar/index.php/visiondefuturo/issue/view/16

ISSN 1668 - 8708 - Versión en Línea

E-mail: revistacientifica@fce.unam.edu.ar
} 
a tasas de interés reducidas, gracias al bajo riesgo país que hoy presenta Chile.

En gran medida, el FUT puede entenderse hoy como una transferencia a las empresas $y$, por ende, a sus dueños. En este sentido, un empresario invertirá hasta donde el beneficio del último peso (\$) sea igual al costo de oportunidad de ese peso. Dado que se tiene un sistema financiero desarrollado y abierto al mundo, el costo de oportunidad de este último peso está determinado por las condiciones de los mercados financieros internacionales. A pesar de que parte de la inversión se realiza con re-inversión de utilidades, el último peso invertido para la mayoría de las empresas se financia con fondos externos a la misma. Por esto, en términos económicos, el FUT afecta, mayoritariamente, de manera infra-marginal la inversión, es decir, no la decisión en el margen, que es la que determina el último peso invertido.

Es importante resaltar que la eliminación del mecanismo del FUT no afectará a las pequeñas empresas, según el tributarista experto de la Universidad de Talca, González, en charla del 2014. Al considerar la información del SII (Servicio de Impuestos Internos) para el año 2012, donde el 95\% de las empresas registra ventas menores a \$506 millones en el año, los cambios que introduce la reforma tributaria y que permiten pasar a una base devengada no las afectarán e incluso las empresas de menor tamaño se podrán ver favorecidas.

El nuevo sistema sobre base devengada no constituye, en esencia, una novedad, dado que en la actual Ley sobre Impuesto a la Renta ya existe un sistema similar, reglado expresamente en la letra b, del artículo 14, al que el año 2012 se acogieron 195.000 empresas.

Para transitar a este nuevo sistema de tributación de la renta sobre base devengada, se deben considerar las siguientes reglas en el tiempo:

- Régimen permanente: que se regula en detalle en las modificaciones a la Ley sobre Impuesto a la Renta contenidas en el artículo $1^{\circ}$ del proyecto, y que entra a regir en el año comercial 2017, para aplicarse, en propiedad, durante el año tributario 2018.

- Transición hasta el 31 de diciembre de 2016: cuyas reglas están contenidas en los artículos segundo y cuarto transitorios.

Tambien se analizará un tema en particular de la Reforma Tributaria, el cual a través del Artículo $6^{\circ}$ de esta reforma, plantea la derogación del Decreto Ley $N^{\circ} 600$ de 1974 Estatuto de la Inversión Extranjera.

Para realizar un análisis detallado, primeramente se presentará el marco legal que rige el Decreto Ley $\mathrm{N}^{\circ} 600$, detallando la personalidad jurídica que puede poseer el inversionista, los derechos y obligaciones que posee tanto el Estado de Chile como el inversionista

\footnotetext{
"Visión de Futuro" Año 16, Volumen N²3 N², Julio - Diciembre 2019 - Pág. 1 - 20

URL de la Revista: http://visiondefuturo.fce.unam.edu.ar/index.php/visiondefuturo/index

URL del Documento: http://visiondefuturo.fce.unam.edu.ar/index.php/visiondefuturo/issue/view/16

ISSN 1668 - 8708 - Versión en Línea

E-mail: revistacientifica@fce.unam.edu.ar
} 
extranjero al suscribir dicho contrato, los derechos que poseen los inversionistas extranjeros, tales como: acceso al mercado cambiario formal, remesa de capital y utilidades, acceso a todos los sectores económicos, recursos de reclamación por discriminación, elección del régimen tributario, impuestos indirectos e invariabilidad, impuesto específico a la actividad minera.

Además se describirán las diferentes formas de ingreso de capital que posee el inversionista extranjero, este capital puede llegar a nuestro país con diferentes formas de transferencia, las cuales pueden ser: en divisa extranjera, bienes físicos, tecnología, créditos asociados a la inversión, capitalización de créditos y deudas externas y capitalización de utilidades.

Sumado a lo anterior, se presentarán los indicadores económicos de la inversión extranjera en nuestro país, los cuales se han acogido al Estatuto. Para una mejor comprensión, se entregarán indicadores económicos de las áreas de la actividad productiva que han recibido más inversión extranjera, como también, los países que han realizado mayor aporte a la economía.

Para poseer un perfil técnico de la Reforma Tributaria, específicamente en lo que respecta al Decreto Ley $N^{\circ} 600$, se expondrá, en forma resumida, el informe de la comisión modernizadora D.L. 600, donde connotados especialistas e invitados plasman sus opiniones con respecto al Estatuto. Esta comisión fue realizada dentro del debate de la Ley 20.469, introduce modificaciones a la Tributación de la Actividad Minera, el año 2010.

Finalmente, y de acuerdo a los antecedentes recopilados, se expresará una visión de la derogación del Decreto Ley № 600 Estatuto de la Inversión Extranjera. La derogación de este Estatuto puede ser un gran desafío para el país, debido a que la inversión extranjera no solo se captará en función de las características económicas y tributarias, sino que también por factores humanos, tecnológicos y de sustentabilidad de nuestros recursos.

Dentro de la Reforma Tributaria, en el Artículo $6^{\circ}$ se derogará el Decreto Ley $N^{\circ} 600$, de 1974 Estatuto de la Inversión Extranjera. La derogación será a partir del $1^{\circ}$ de enero de 2016, por lo tanto, el Comité de Inversiones Extranjeras (CIE), dejará de celebrar nuevos contratos de inversión extranjera. Los contratos ya suscritos con el comité, continuarán rigiéndose por las normas legales vigentes aplicables a los contratos.

Después de la nacionalización del cobre en el año 1971, durante el gobierno del Presidente Salvador Allende G., se produjo la estatización de empresas extranjeras relacionadas con este mineral. Posteriormente, con el golpe de Estado y la formación de la junta militar, se debió crear un nuevo mecanismo de transferencia de capitales hacia Chile, que permitiera al inversionista extranjero tener seguridad e incentivo para realizar proyectos

\footnotetext{
“Visión de Futuro" Año 16, Volumen Nº 23 N², Julio - Diciembre 2019 - Pág. 1 - 20

URL de la Revista: http://visiondefuturo.fce.unam.edu.ar/index.php/visiondefuturo/index

URL del Documento: http://visiondefuturo.fce.unam.edu.ar/index.php/visiondefuturo/issue/view/16

ISSN 1668 - 8708 - Versión en Línea

E-mail: revistacientifica@fce.unam.edu.ar
} 
en el país. Por estas razones, en el año 1974, se crea el decreto Ley $\mathrm{N}^{\circ} 600$, donde el inversionista extranjero es beneficiado por una invariabilidad tributaria, es decir, no es afectado por alzas en el impuesto adicional cuando se realice una modificación o reforma tributaria.

El análisis de la importancia del Decreto Ley $N^{\circ} 600$ se comienza a debatir en el congreso de Chile posterior al terremoto del año 2010, en ocasión de la tramitación de la Ley 20.469 Introduce modificaciones a la tributación de la actividad minera, donde se crea la comisión modernización DL 600, formada por miembros nacionales de alto nivel y en donde se invitó a exponer a distintos expertos relacionados con la inversión extranjera. La formación de esta comisión será un excelente aporte para determinar si el Decreto Ley $\mathrm{N}^{\circ}$ 600 cumplió su etapa y puede revisarse, además, por el contexto histórico de menor riesgo en el que se encuentra el país para los inversionistas extranjeros.

El Decreto Ley 600 (DL 600), empieza su vigencia en el año 1974, permitiendo una transferencia de capital extranjero hacia Chile. A través de un régimen voluntario, los inversores extranjeros que ingresan capitales, ya sean bienes físicos o de otra forma de inversión, solicitan suscribir un contrato de inversión extranjera con el Estado de Chile.

Los inversores extranjeros pueden acogerse al DL 600 según las siguientes formas:

a) Personas naturales y extranjeras.

b) Personas jurídicas extranjeras, las cuales pueden ser: personas jurídicas de derecho privado, personas jurídicas de derecho público, Estados extranjeros y organizaciones internacionales.

c) Personas naturales y jurídicas chilenas con residencia y domicilio en el exterior.

Este estatuto establece un contrato entre el Estado de Chile y los inversores extranjeros, instaurando derechos y obligaciones entre ambas partes, este no puede ser modificado ni dejado sin efecto unilateralmente por ninguna de las partes que suscriben dicho contrato.

Los derechos que otorga el decreto DL 600 son los siguientes:

- Acceso al mercado cambiario formal; el inversionista extranjero tiene garantizado el acceso al mercado cambiario formal (bancos y casas de cambio autorizadas), tanto para liquidar divisas del aporte de capital como también para adquirir divisas a remesar por concepto de capital o utilidad.

- Remesa de capital y utilidades; después de un año desde transcurrido el ingreso del capital extranjero el inversionista puede remesar. Dicha remesa está exenta de toda contribución, impuesto o gravamen, hasta el monto de la inversión materializada.

- Acceso a todos los sectores económicos; los inversionistas podrán desarrollar todo

\footnotetext{
"Visión de Futuro" Año 16, Volumen N²3 N², Julio - Diciembre 2019 - Pág. 1 - 20

URL de la Revista: http://visiondefuturo.fce.unam.edu.ar/index.php/visiondefuturo/index

URL del Documento: http://visiondefuturo.fce.unam.edu.ar/index.php/visiondefuturo/issue/view/16

ISSN 1668 - 8708 - Versión en Línea

E-mail: revistacientifica@fce.unam.edu.ar
} 
tipo de actividades económicas respetando las normas legales vigentes.

- Recurso de reclamación por discriminación; garantiza al inversionista extranjero la aplicación de las mismas leyes y reglamentos que se les aplica a los inversionistas locales en la misma actividad productiva.

- Elección de régimen tributario; los inversionistas extranjeros están afectos a un impuesto adicional a la remesa de utilidades y pueden optar a opciones que son las de régimen común 35\% como impuesto a primera categoría, el cual opera como crédito a favor del inversionista o el régimen de invariabilidad tributaria (opcional) $42 \%$ el cual constituye en un seguro tributario en donde no se varía la tasa por 10 años. Este último régimen se puede renunciar por una sola vez y quedará afecto al régimen impositivo común.

- Impuestos indirectos; debido a la invariabilidad de los contratos en el período en que se realiza la inversión, en donde el régimen tributario del impuesto sobre las ventas y servicio y el régimen arancelario aplicable a maquinaria y equipos que no se producen en el país. Los bienes que cumplen tales condiciones quedan exentos del pago de IVA.

- Invariabilidad impuestos específicos a la actividad minera; el artículo 11 ter del DL 600 indica un régimen de invariabilidad del impuesto específico a la actividad minera para aquellas inversiones que sobrepasan los US\$ 50 millones. Los inversionistas no deben estar amparados a los regímenes de invariabilidad establecidos en los artículos 7 y 11 bis del DL 600 , si lo estuvieran deben renunciar a ellos y acogerse al artículo 11 ter. El artículo $7^{\circ}$ ter hace referencia a la mantención por un plazo de 10 años de la tasa de impuesto a la renta a que están sujetos.

Los capitales extranjeros que ingresen a Chile podrán internarse y deberán valorizarse de las siguientes formas:

a) Moneda extranjera de libre convertibilidad.

b) Bienes físicos, en todas sus formas o estados.

c) Tecnología en sus diversas formas cuando sean susceptibles de ser capitalizadas.

d) Créditos que vengan asociados a una inversión extranjera.

e) Capitalización de créditos y deudas externas.

f) Capitalización de utilidades con derecho a ser transferidas al exterior.

El 6 de octubre del año 2010 y con ocasión de la tramitación de la Ley 20.469 que introduce modificaciones a la tributación de la actividad minera, se alcanzó un acuerdo entre los senadores de la Comisión de Hacienda del Senado y los Ministros de Hacienda y Minería, tendiente, entre otros, a la formación de una Comisión de alto nivel que estudiara la modernización del Decreto Ley 600.

Sin dejar de mencionar que el cuidado del medio ambiente ha ido generando,

\footnotetext{
“Visión de Futuro" Año 16, Volumen Nº 23 N², Julio - Diciembre 2019 - Pág. 1 - 20

URL de la Revista: http://visiondefuturo.fce.unam.edu.ar/index.php/visiondefuturo/index

URL del Documento: http://visiondefuturo.fce.unam.edu.ar/index.php/visiondefuturo/issue/view/16

ISSN 1668 - 8708 - Versión en Línea

E-mail: revistacientifica@fce.unam.edu.ar
} 
paulatinamente, mayor conciencia en las personas, el calentamiento global se ha insertado como tema de discusión a nivel internacional, la globalización del mundo es algo real, las campañas a su favor y la creación de sistemas autosustentables está aumentando la sensibilidad respecto a este tema.

El gobierno, a través del ejecutivo, ha propuesto al poder legislativo, el día 01 de abril del presente año, un proyecto de ley que modificará el sistema tributario, con la finalidad de: financiar reformas educacionales, avanzar en la equidad tributaria, incentivar el ahorro y la inversión y disminuir la evasión y la elusión.

Este proyecto de ley hace referencia al tema del medio ambiente, estableciendo impuestos aplicados a los emisores de gases contaminantes de fuentes fijas y vehículos que utilizan diésel como combustible.

Este proyecto no establece medidas concretas respecto a incentivos tributarios para la creación de proyectos destinados a la generación de energías por sistemas no convencionales y renovables, con el fin de reducir, efectivamente, las emisiones contaminantes y aprovechar, eficientemente, los recursos ilimitados provenientes de grandes fuentes naturales, como son: el mar, el viento, el sol y la geotermia.

De igual forma, no presenta proposiciones para incentivar la preservación de los recursos naturales existentes en el territorio de Chile. Toman especial interés aquellos recursos que son renovables y que, de ser explotados de manera racional, son perdurables en el tiempo. Es primordial establecer una política fuerte del gobierno que, mediante la herramienta de los impuestos, genere todas las condiciones posibles para la real protección del medio ambiente.

En este sentido, la reforma tributaria busca, como objetivo fundamental, financiar en forma permanente la reforma educacional, avanzar con la equidad tributaria, la incorporación de mecanismos de incentivos al ahorro de la inversión y, finalmente, avanzar en Leyes efectivas que disminuyan la evasión y elusión.

\section{Análisis y resultados}

A continuación, se encuentra un resumen de las principales modificaciones 0 diferencias y sus impactos, del sistema propuesto por la reforma versus el sistema actual.

Tabla №1. Principales modificaciones de la Reforma al Impuesto a la Renta

\begin{tabular}{|c|l|l|}
\hline № & \multicolumn{1}{|c|}{ Item Modificado } & \multicolumn{1}{c|}{ Principales Modificaciones } \\
\hline \multirow{2}{*}{1} & $\begin{array}{l}\text { Aumento de la Tasa del } \\
\text { Impuesto de Primera } \\
\text { Categoría: }\end{array}$ & $\begin{array}{l}\text { Se aumenta gradualmente, de 20\% a 25\% la tasa del Impuesto de } \\
\text { Primera Categoría (21\% en 2014, 22,5\% en 2015, 24\% en 2016, } \\
\text { para llegar al 25\% en 2017). }\end{array}$ \\
\hline
\end{tabular}

\footnotetext{
"Visión de Futuro" Año 16, Volumen N²3 N², Julio - Diciembre 2019 - Pág. 1 - 20

URL de la Revista: http://visiondefuturo.fce.unam.edu.ar/index.php/visiondefuturo/index

URL del Documento: http://visiondefuturo.fce.unam.edu.ar/index.php/visiondefuturo/issue/view/16

ISSN 1668 - 8708 - Versión en Línea

E-mail: revistacientifica@fce.unam.edu.ar
} 


\begin{tabular}{|c|c|c|}
\hline & \multirow[b]{2}{*}{$\begin{array}{l}\text { Tributación sobre base } \\
\text { devengada /Eliminación } \\
\text { del Fondo de Utilidades } \\
\text { Tributables (FUT): }\end{array}$} & $\begin{array}{l}\text { Con la tributación sobre base devengada se elimina el FUT de } \\
\text { forma definitiva a partir del año comercial } 2017 .\end{array}$ \\
\hline 2 & & $\begin{array}{l}\text { También se agrega un impuesto de retención equivalente al 10\% } \\
\text { en la sociedad fuente en que se generan las utilidades atribuibles; y } \\
\text { en caso que las rentas sean atribuidas a un contribuyente no } \\
\text { residente o domiciliado en Chile, la retención será igual a la } \\
\text { diferencia entre } 35 \% \text { y la tasa de Impuesto de Primera Categoría. }\end{array}$ \\
\hline 3 & Impuestos Personales & $\begin{array}{l}\text { A partir del año } 2017 \text {, la tasa máxima de los impuestos personales, } \\
\text { esto es, Impuesto de Segunda Categoría e Impuesto Global } \\
\text { Complementario, se reduce del actual } 40 \% \text { a un } 35 \% \text {. }\end{array}$ \\
\hline \multirow{5}{*}{4} & \multirow{5}{*}{$\begin{array}{l}\text { Tributación de las } \\
\text { Ganancias de Capital }\end{array}$} & $\begin{array}{l}\text { i) Toda ganancia de capital quedará gravada con el impuesto a la } \\
\text { renta. }\end{array}$ \\
\hline & & $\begin{array}{l}\text { ii) Se elimina la exención a las ganancias de capital proveniente de } \\
\text { la enajenación de bienes raíces. }\end{array}$ \\
\hline & & $\begin{array}{l}\text { iii) En relación al costo de las acciones y derechos sociales, se } \\
\text { reconoce como parte de éste, las utilidades retenidas y atribuidas } \\
\text { en la sociedad entre la fecha de adquisición y la fecha de } \\
\text { enajenación de las acciones o derechos sociales. }\end{array}$ \\
\hline & & $\begin{array}{l}\text { iv) En caso de adquisición de acciones o derechos financiados con } \\
\text { deuda, los intereses no serán deducibles de la base imponible del } \\
\text { impuesto de primera categoría, pero incrementarán el costo de } \\
\text { adquisición de dichos derechos o acciones. }\end{array}$ \\
\hline & & $\begin{array}{l}\text { v) Se modifica la tributación de las ganancias de capital que } \\
\text { distingue entre ganancias habituales y no habituales. Se establece } \\
\text { un tratamiento diferenciado de acuerdo al plazo de tenencia de } \\
\text { estos bienes (Inferior o Igual a un año; y Superior a un año). }\end{array}$ \\
\hline 5 & Tributación de Fondos & $\begin{array}{l}\text { Se modifica la Ley Única de Fondos (Ley } 20.712 \text { ), recientemente } \\
\text { aprobada por el Congreso, cambiando el régimen tributario y } \\
\text { gravando a los tenedores de cuotas de fondos sobre base } \\
\text { devengada o atribuida. Las sociedades administradoras deberán } \\
\text { retener, declarar y pagar un } 10 \% \text { sobre el valor total del resultado } \\
\text { tributario obtenido por el Fondo. } \\
\text { En relación a los Fondos de Inversión Privado, la administradora } \\
\text { deberá practicar una retención del } 35 \% \text { de toda la utilidad } \\
\text { devengada del fondo. }\end{array}$ \\
\hline \multirow{4}{*}{6} & \multirow{4}{*}{$\begin{array}{l}\text { Normas sobre Tributación } \\
\text { Internacional }\end{array}$} & $\begin{array}{l}\text { i) Reglas CFC (Controlled Foreign Corporation): Se establece una } \\
\text { norma que evita que se difiera el pago de impuestos sobre rentas } \\
\text { pasivas de fuente extranjera. }\end{array}$ \\
\hline & & ii) Residencia: incorpora el concepto de beneficiario efectivo. \\
\hline & & $\begin{array}{l}\text { iii) Deducción de gastos incurridos en el extranjero con partes } \\
\text { relacionadas: Sólo en la medida que el gasto se haya pagado y se } \\
\text { haya retenido el impuesto adicional al que se puedan encontrar } \\
\text { afectos. }\end{array}$ \\
\hline & & $\begin{array}{l}\text { iv) Normas de exceso de endeudamiento: Nueva norma para el } \\
\text { cálculo de exceso de endeudamiento que afecta a los intereses y } \\
\text { cualquier otro recargo o gasto financiero, que se pague a entidades } \\
\text { relacionadas del exterior. }\end{array}$ \\
\hline
\end{tabular}

\footnotetext{
"Visión de Futuro" Año 16, Volumen No 23 N², Julio - Diciembre 2019 - Pág. 1 - 20

URL de la Revista: http://visiondefuturo.fce.unam.edu.ar/index.php/visiondefuturo/index

URL del Documento: http://visiondefuturo.fce.unam.edu.ar/index.php/visiondefuturo/issue/view/16

ISSN 1668 - 8708 - Versión en Línea

E-mail: revistacientifica@fce.unam.edu.ar
} 


\begin{tabular}{|c|c|c|}
\hline 7 & $\begin{array}{l}\text { Mejoras a los mecanismos } \\
\text { de depreciación }\end{array}$ & $\begin{array}{l}\text { Se introduce un mecanismo de depreciación instantánea disponible } \\
\text { para las micro y pequeñas empresas. Las medianas empresas } \\
\text { podrán acceder al mecanismo de depreciación especial. }\end{array}$ \\
\hline \multirow{4}{*}{8} & \multirow{4}{*}{$\begin{array}{l}\text { Reglas especiales para } \\
\text { pequeñas empresas }\end{array}$} & $\begin{array}{l}\text { i) Ampliación de los beneficios del Artículo 14ter: Podrán acceder a } \\
\text { este régimen, todas las empresas individuales y personas jurídicas } \\
\text { cuyas ventas anuales no excedan de } 25.000 \text { UF. } \\
\text { Se eliminan los regímenes simplificados contenidos en los artículos } \\
14 \text { bis y } 14 \text { quater de la Ley sobre Impuesto a la Renta. }\end{array}$ \\
\hline & & $\begin{array}{l}\text { ii) Reglas especiales sobre pagos provisionales mensuales (PPM) } \\
\text { Las empresas acogidas al artículo } 14 \text { ter, se encontrarán afectas a } \\
\text { tasas más bajas respecto de sus PPM. } \\
\text { Además, se establece una rebaja transitoria de } 15 \% \text { en el pago de } \\
\text { los PPM para medianas y pequeñas empresas durante los primeros } \\
12 \text { meses desde la entrada en vigencia de la reforma. }\end{array}$ \\
\hline & & $\begin{array}{l}\text { iii) Cambio en el sujeto del pago del IVA: Las grandes empresas } \\
\text { (ventas superiores a } 100.000 \text { UF) podrán asumir como sujetos } \\
\text { pagadores de IVA. }\end{array}$ \\
\hline & & $\begin{array}{l}\text { iv) Crédito por compra de activo fijo: Se aumenta de } 4 \% \text { a } 6 \% \text { (del } \\
\text { monto invertido), el crédito por inversión en activo fijo, respecto de } \\
\text { micro, pequeñas y medianas empresas. Estas últimas con la } \\
\text { salvedad que se les aplica una fórmula lineal en base a la cual, el } \\
\text { beneficio decrece mientras se van acercando al tamaño de gran } \\
\text { empresa. }\end{array}$ \\
\hline
\end{tabular}

Fuente: Elaboración Propia

\section{Otros impuestos modificados por la Reforma}

Impuestos Verdes, se crean impuestos verdes que gravan ciertos bienes que no son amigables con el medio ambiente. Así, se establece un impuesto a las emisiones de fuentes fijas que grava la emisión de ciertos contaminantes y un impuesto adicional a la importación de vehículos livianos más contaminantes que utilicen diésel.

Impuesto Correctivo, se aumenta el impuesto específico a las bebidas alcohólicas, a las bebidas no alcohólicas que presenten elevados contenidos de azúcares y a las energizantes o hipertónicas.

Bienes Inmuebles, se propone gravar con IVA la venta habitual de bienes inmuebles nuevos o usados. Elimina el crédito del artículo 21 del DL 910 de 1975 a viviendas con valor superior a las 2.000 UF y restringe el monto máximo desde 225 UF a 100 UF.

Impuesto de Timbres y Estampillas, se aumenta la tasa máxima del impuesto de timbres y estampillas desde el actual $0,4 \%$ a $0,8 \%$.

\section{Derogación del Decreto Ley $\mathbf{N}^{\circ} \mathbf{6 0 0}$ (Estatuto de Inversión Extranjera)}

La reforma propone derogar el DL No 600 a partir del 1 de enero de 2016, para los nuevos proyectos de inversión. No obstante, los titulares de contratos de inversión ya

\footnotetext{
“Visión de Futuro" Año 16, Volumen Nº 23 N², Julio - Diciembre 2019 - Pág. 1 - 20

URL de la Revista: http://visiondefuturo.fce.unam.edu.ar/index.php/visiondefuturo/index

URL del Documento: http://visiondefuturo.fce.unam.edu.ar/index.php/visiondefuturo/issue/view/16

ISSN 1668 - 8708 - Versión en Línea

E-mail: revistacientifica@fce.unam.edu.ar
} 
suscritos con el Comité de Inversiones Extranjeras, continuarán rigiéndose por las normas legales vigentes aplicables a sus contratos.

\section{Normas para combatir la elusión y evasión tributaria}

Se incorporan las siguientes normas para combatir la elusión y evasión tributaria:

a) Norma General Anti-Elusión que permite al SII rechazar las ventajas tributarias obtenidas mediante planificaciones elusivas, abusivas o simuladas y sancionar a los contribuyentes y asesores tributarios que hayan participado en su diseño.

b) Se establecen normas que facultan al SIl para acceder a la información necesaria para cumplir su misión fiscalizadora.

c) Normas que permiten al SIl acceder a la información de compras pagadas por medios electrónicos (tarjetas de crédito y débito).

\section{CONCLUSION}

Pensar que los impuestos per se tienen influencia sobre la igualdad sería una gran paradoja, dado que la experiencia mundial muestra que si aumentan los impuestos a las personas más ricas, ellos son globalizados, por lo cual tienen la posibilidad de cambiar su riqueza e ingresos a países con menores impuestos; luego se podría pensar que si al aplicar altos impuestos en forma sostenida, los ricos van a desaparecer, incluso si se confisca la riqueza total de los ricos no van a hacer a los pobres más ricos, por lo cual los impuestos como tal no son un instrumento contra la desigualdad, más bien es un mito del siglo XIX, que a través de los impuestos se puede traer equidad, si no más bien, son solo un medio distributivo para generar trabajo y mejorar la educación, que sí son elementos que generan equidad.

Es por lo anterior que la reforma transcendental en Chile sería la reforma a la educación, financiada por la reforma tributaria, pero no de toda la educación, si no más bien, de la educación pública básica, dado que, el economista y filosofo francés Guy Sorman (2015) asegura, que en Chile la mitad de la población no está participando realmente del progreso social y económico desde hace 30 años, porque esas personas vienen de un pasado pobre, generalmente, de provincias lejanas que no se pueden beneficiar del progreso, porque no tienen acceso a una educación básica decente, están estancados en mediocres y malas escuelas públicas, donde la prioridad debería ser darles una educación apropiada, ya sea pública o privada subvencionada. Así se incorpora a esta población que permanece pobre por la precaria educación.

\footnotetext{
“Visión de Futuro" Año 16, Volumen Nº 23 N², Julio - Diciembre 2019 - Pág. 1 - 20

URL de la Revista: http://visiondefuturo.fce.unam.edu.ar/index.php/visiondefuturo/index

URL del Documento: http://visiondefuturo.fce.unam.edu.ar/index.php/visiondefuturo/issue/view/16

ISSN 1668 - 8708 - Versión en Línea

E-mail: revistacientifica@fce.unam.edu.ar
} 
La actual reforma, debido a lo extenso de su interpretación, dado que cada modificación, necesariamente, remite al artículo original de la ley que se modifica y al desconocimiento técnico de esta, no muchos visualizan los puntos de importancia de la reforma, y que, a evaluación personal, se contradicen con el querer avanzar en la equidad tributaria por derecho y en mejorar la distribución del ingreso.

Existen reformas destinadas a derrumbar los pocos beneficios que el Estado aún entrega a la clase media, construyendo una trinchera profunda de donde el pequeño empresario deberá intentar salir con una ayuda nefasta del sistema financiero por las altas tasas de interés a las que accede, apoyo insuficiente dado que nunca financiarán el 100\% de sus requerimientos financieros nuevos, por el riesgo crediticio que ello implica y burocrático, dado que no existe historia del rendimiento de las empresas pequeñas bajo este nuevo escenario tributario, por lo cual alargará el período de análisis de riesgo de crédito necesario para la aprobación de nuevos fondos bancarizables.

Nada se dice del efecto que la reforma tendrá sobre los cotizantes de Fondos de Pensiones, que se estima en una baja del $6 \%$ de sus pensiones futuras. Esta baja sustancial será consecuencia de que los Fondos de Pensiones no pueden transferir a sus afiliados el crédito del Impuesto de Primera Categoría que afecta a los dividendos de acciones que perciben y que con la reforma en curso llegaría a una carga real de un 35\%.

Por lo tanto, esta reforma atentará directamente contra los cotizantes de menores ingresos, aún estando ellos exentos del Impuesto Global Complementario o afectos a una tasa efectiva del $2 \%$, terminarán soportando una carga del $35 \%$ por la obtención de estos dividendos.

Más del $70 \%$ de los trabajadores y cotizantes de bajos ingresos deberán soportar la carga tributaria del $35 \%$ por los beneficios que sus fondos de pensiones obtengan, la misma carga que la Ley de la Renta contempla para las grandes empresas internacionales y las personas de mayor ingreso del país.

A mayor esfuerzo en intentar ver como esta medida permite avanzar en la equidad tributaria y mejorar la distribución del ingreso, más se hace evidente que esta reforma trae cambios que afectan gravemente a nuestra clase media.

Así observamos la derogación del artículo 57 bis que beneficia e incentiva el ahorro, el aumento al doble del Impuesto de Timbres que afecta a créditos hipotecarios y de consumo, la eliminación del beneficio que frente al IVA tienen los inmuebles con valor superior a las 2.000 UF, la propuesta de afectar con IVA la venta de bienes inmuebles de todo tipo, incluidos los destinados a la vivienda, la afectación con impuesto a la renta de la ganancia que una persona natural pueda tener en la venta de un inmueble que ha adquirido con el

\footnotetext{
“Visión de Futuro" Año 16, Volumen Nº 23 N², Julio - Diciembre 2019 - Pág. 1 - 20

URL de la Revista: http://visiondefuturo.fce.unam.edu.ar/index.php/visiondefuturo/index

URL del Documento: http://visiondefuturo.fce.unam.edu.ar/index.php/visiondefuturo/issue/view/16

ISSN 1668 - 8708 - Versión en Línea

E-mail: revistacientifica@fce.unam.edu.ar
} 
ánimo de inversión para su vejez, la creación de un nuevo impuesto que afectará a todo vehículo diésel particular, etc.

Tal como mencionamos al inicio de este informe, consideramos que son necesarios cambios que reduzcan la brecha de la desigualdad de ingresos y oportunidades arraigadas históricamente en nuestro país, siendo positivos los cambios o reformas que potencien las capacidades intelectuales y profesionales de cada ciudadano que ejerza su derecho de emprender y superarse a diario, siendo para ello como base fundamental una educación gratuita, de calidad y de oportunidad equitativa, no influenciada por entes externos.

Tal como indica el Senador Zaldívar (2014), en una entrevista dada al Diario el Mercurio, el miércoles 21 de mayo del 2014: "El corazón de la Reforma Tributaria es susceptible de mejoras", afirmando que en la Cámara Alta los puntos centrales del proyecto, como el alza de impuestos a las empresas y la eliminación del FUT, sí serán analizados.

Por tanto, podemos concluir que la reforma tributaria es necesaria en base a la situación histórica de nuestro país, en aras de una buscada igualdad ciudadana, pero es necesario mejorar varios aspectos de este proyecto, para que no se transforme en una reforma ideal en su estructura escrita, pero un fracaso al momento aplicarla y llevarla a cabo, transformándose en un nuevo TranSantiago.

\section{REFERENCIAS BIBLIOGRÁFICAS}

Santos, L. (07 de abril de 2014). Reforma tributaria. El Pulso. Recuperado de: http://www.pulso.cl/noticia/economia/economia/2014/04/7-41117-9-reforma-tributariacambios-al-impuesto-a-la-renta-recaudaran-en-torno-a-us3800.shtml

Cándido, M. (7 de abril 2014). Reforma Tributaria. La Tercera. Recuperado de: http://diario.latercera.com/2014/04/07/01/contenido/negocios/10-161674-9-impuestossobre-base-devengada-y-fin-del-fut.shtml

Cabezas, D. (02 de abril 2014). La postura del sector agrícola. Recuperado de: http://eltipografo.cl/2014/04/la-postura-del-sector-agricola/

Ciper Chile. (2014). La radiografía del cerebro tributario de Bachelet al 1\% más rico de Chile. Recuperado de: http://ciperchile.cl/2014/02/14/el-\%E2\%80\%9C1\%E2\%80\%9Dchileno-segun-el-cerebro-tributario-de-bachelet-enorme-riqueza-pequenos-impuestos Comisión Nacional del Medio Ambiente. (2009). Guía metodológica para la estimación de emisiones atmosféricas de fuentes fijas y móviles en el registro de emisiones y transferencia de contaminantes.

\footnotetext{
“Visión de Futuro" Año 16, Volumen Nº 23 N², Julio - Diciembre 2019 - Pág. 1 - 20

URL de la Revista: http://visiondefuturo.fce.unam.edu.ar/index.php/visiondefuturo/index

URL del Documento: http://visiondefuturo.fce.unam.edu.ar/index.php/visiondefuturo/issue/view/16

ISSN 1668 - 8708 - Versión en Línea

E-mail: revistacientifica@fce.unam.edu.ar
} 
Comité de Inversiones Extranjeras. (2012). DL 600. Recuperado de: http://www.ciechile.gob.cl/es/dl-600/que-es-el-dl600/

Comité de Inversiones Extranjeras. (2011). Estadísticas. Recuperado de: http://www.ciechile.gob.cl/es/inversion-en-chile/estadisticas/

Comité de Inversiones Extranjeras. (2012). Informe Comisión Modernización D.L. 600.

Recuperado

de:

http://www.ciechile.gob.cl/wpcontent/uploads/2010/10/Informe_final_Comisin_Moderniz adora_DL600.pdf

Cross Plaza Tax Compliance \& BPO (2014) Eliminación del FUT. Recuperado de: http://www.crossplaza.cl/eliminacion-del-fut/

Sarmiento, L. (2012). Curso práctico de Impuesto a la Renta, editorial CEPET, 6 ediciones, año 2009.

Dirección de Presupuesto del Ministerio de Hacienda. (01-04-2014). Informe № 38.

Fundación Heinrich Böll S. Cono Sur. (2012). Programa Chile sustentable. Recuperado de: http://antiguo.minenergia.cl/minwww/opencms/14_portal_informacion/la_energia

González, S. (octubre, 2014). Reforma tributaria en Chile. Charla realizada en campus Curicó de la Universidad de Talca, Chile.

InvestChile. (2012). Estatuto de la Inversión Extranjera - Decreto Ley 600. Recuperado de: http://www.ciechile.gob.cl/wp-content/uploads/2010/10/dl600_espanol1.pdf

Ley $N^{\circ} 20.469$ - Introduce modificaciones a la Tributación de la Actividad Minera. Diario Oficial de la República de Chile, Santiago de Chile, 20 de junio 2011.

Ley sobre Impuestos a la Renta, edición 2012. Diario Oficial de la República de Chile. 15 de julio 2012.

MINSAL. (2012). Efectos de la fracción gruesa (PM10-2.5) del material particulado sobre la salud humana. Revisión Bibliográfica. Recuperado de: http://planesynormas.mma.gob.cl/archivos/2016/proyectos/Efectos_en_la_salud_partic ulado_Claudio_Vargas_2011_MINSAL.pdf

Michelle Bachelet Jeria - Reforma Tributaria. Página Consultada: http://michellebachelet.cl/wp-content/uploads/2013/10/Reforma-Tributaria-22-27.pdf OCDE. (2009). Reformas tributarias ambientales en países de la Organización de Cooperación y Desarrollo Económicos. Recuperado de: http://www.ciechile.gob.cl/wpcontent/uploads/2010/10/dl600_espanol1.pdf

Publicaciones EMB. (2011). Eliminación del FUT: Pro y contras. Recuperado de: http://www.emb.cl/dinero/articulo.mvc?xid=974

\footnotetext{
"Visión de Futuro" Año 16, Volumen Nº 23 N², Julio - Diciembre 2019 - Pág. 1 - 20

URL de la Revista: http://visiondefuturo.fce.unam.edu.ar/index.php/visiondefuturo/index

URL del Documento: http://visiondefuturo.fce.unam.edu.ar/index.php/visiondefuturo/issue/view/16

ISSN 1668 - 8708 - Versión en Línea

E-mail: revistacientifica@fce.unam.edu.ar
} 
Proyecto de Ley de Reforma Tributaria, que modifica el sistema de tributación a la renta, 1 de abril de 2014.

Reforma Tributaria - Artículo 1, el corazón de la Reforma Tributaria 17/04/2014 http://reformatributaria.gob.cl/

Reforma Tributaria - Indicaciones proyecto de Reforma Tributaria 16/04/2014 http://reformatributaria.gob.cl/

Reforma Tributaria - Proyecto de Reforma Tributaria 01/04/2014 http://reformatributaria.gob.cl/

Rodríguez, C. (26 de mayo de 2014.) Agro: Cambio a régimen tributario de renta presunta afectaría a más de 40 mil pymes. Economía y Negocios. Recuperado de: http://www.economiaynegocios.cl/noticias/noticias.asp?id=119947

Salamanca, J. (miércoles 27 de junio de 2012). Ruta de la sustentabilidad. La segunda. Recuperado de: http://www.estrategia.cl/especiales/2011/ESP_Huella_de_Carbono.pdf Sorman, G. (agosto, 2015). Los impuestos no tienen influencia sobre la igualdad. Entrevista realizada para CNN Chile.

Valenzuela, S. (2014). La reforma tributaria en el agro. Saval FG. Recuperado de: http://www.savalfg.cl/noticias/134-la-reforma-tributaria-en-el-agro.html

\section{RESUMEN BIOGRAFICO}

\section{Oscar Alfredo Rojas Carrasco}

PhD en Economía y Finanzas en Atlantic International University, Hawaii, Estados Unidos, Post Doctor (c) en Finanzas, Doctorando en Educación, Máster en Educación, Máster Business Administration, Ingeniero Comercial, Licenciado en Ciencias de la Administración, Académico departamento de Investigación y Postgrado, Universidad Miguel de Cervantes, Santiago, Chile.

\section{Fernando Alejandro Herrera Ciudad}

Máster en Finanzas de la Universidad de Chile, Doctorando en Educación, Magister en Educación, Ingeniero Comercial, Licenciado en Ciencias de la Administración, Académico, Departamento de Investigación y Postgrado Universidad Miguel de Cervantes, Santiago, Chile.

\section{Albino Enzon González González}

Magister en Educación mención en Gestión de la Calidad de la Universidad Miguel de Cervantes, Doctorando en Educación, Ingeniero en Administración, Licenciado en Ciencias de la Administración, Académico, Departamento de Investigación y Postgrado, Universidad Miguel de Cervantes, Santiago, Chile.

\footnotetext{
“Visión de Futuro" Año 16, Volumen Nº 23 N², Julio - Diciembre 2019 - Pág. 1 - 20

URL de la Revista: http://visiondefuturo.fce.unam.edu.ar/index.php/visiondefuturo/index

URL del Documento: http://visiondefuturo.fce.unam.edu.ar/index.php/visiondefuturo/issue/view/16

ISSN 1668 - 8708 - Versión en Línea

E-mail: revistacientifica@fce.unam.edu.ar
} 